\title{
PERCEPÇÃO AMBIENTAL EM PROPRIEDADES RURAIS: Palmas (TO), Brasil
}

\author{
environmental perception in rural properties: Palmas (TO), Brazil
}

\author{
Nascimento Marques de Miranda* \\ Lucas Barbosa e Souza**
}

\section{Resumo}

Esta investigação enfoca a percepção ambiental em propriedades rurais por meio de uma abordagem no município de Palmas (TO). Para tanto, empregou-se técnicas para coleta de dados subjetivos, como questionários, entrevistas e observação indireta, além da análise de documentos voltados à caracterização geográfica da área da pesquisa. De modo geral, os principais resultados apontaram que a percepção dos sujeitos em relação ao ambiente e aos recursos naturais de suas propriedades é baseada principalmente nas suas experiências locais, em detrimento das preocupações ambientais de ordem técnica ou jurídica. A maioria dos sujeitos possui uma concepção estritamente ecológica e utilitária do meio ambiente, na qual se ressalta o uso dos recursos naturais.

Palavras-chave: Percepção ambiental, Recursos naturais, Propriedades rurais.

\begin{abstract}
This research focuses on environmental awareness in rural properties through an approach in the city of Palmas (TO). To this end, we used techniques for collecting subjective data, such as questionnaires, interviews and indirect observation, instead of the analysis of documents focused on the geographic characterization of the area of research. Overall, main results showed that the subjects' perception towards the environment and natural resources of their properties is based mainly on their local experiences, to the detriment of environmental concerns of a technical or legal order. Most subjects have a strictly ecological and utilitarian conception of the environment in which it stresses the use of natural resources.
\end{abstract}

Key words: Environmental Perception, Natural resources, Rural properties.

\section{Resumen}

Esta investigación se centra en la percepción del ambiente natural en las propiedades rurales a través de un enfoque en el municipio de Palmas (TO). Para ello, se utilizó técnicas de recogida de datos subjetivos, tales como cuestionarios, entrevistas y la observación indirecta, además del análisis de los documentos que abordan la caracterización de la zona geográfica de la investigación. En general, los resultados mostraron que la percepción de los sujetos en relación el medio ambiente y los recursos naturales de sus propiedades se basan principalmente en sus experiencias locales, en detrimento de las preocupaciones ambientales de carácter técnico o legal. La mayoría de los sujetos tienen una concepción estrictamente ecológica y utilitaria del entorno en el que se destaca el uso de los recursos naturales.

Palabras clave: Percepción ambiental, Recursos naturales, Propiedades rurales.

(*) Mestre em Ciências do Ambiente pela Fundação Universidade Federal do Tocantins - Campus de Porto Nacional, Rua 7 , Quadra 15, s/n. - CEP: 77500-000, Porto Nacional (TO), Brasil, Tel. (+55 63) 3363-0504 - nascimentogeo@uft.edu.br

(**) Prof. Dr. da Fundação Universidade Federal do Tocantins - Rua 07, quadra 15 s/nº, Jardim dos Ipês, $77500-000$ - Porto Nacional (TO) - Brasil, Te/Fax: (+55 63) 33630504 / 33630501 - lbsgeo@uft.edu.br 


\section{INTRODUÇÃO}

A abordagem objetiva do meio ambiente, apesar de contribuir para o seu conhecimento sob o ponto de vista da racionalidade científica, tem se mostrado insuficiente para provocar mudanças significativas na conduta do homem, em termos ambientais (RIBEIRO, 2000). Logo, o estudo da subjetividade, por meio da percepção ambiental, é de fundamental importância para compreender melhor a inter-relação entre os indivíduos e o meio ambiente, bem como suas expectativas, satisfações, julgamentos e condutas.

Dessa forma, para compreender tal relação (entre o homem e a natureza) torna-se de fundamental importância conhecer como cada indivíduo percebe e responde às várias manifestações do meio ambiente. Embora a percepção seja um processo pessoal, o indivíduo não age isoladamente num determinado ambiente, mas de forma coletiva e faz parte de um grupo com comportamentos e características geralmente semelhantes. Daí advém a importância de estudar a percepção ambiental dos diversos grupos sociais existentes, com suas vivências, valores, condutas e comportamentos. Whyte (1977) ressalta ainda que projetos de percepção ambiental podem contribuir para uma melhor utilização dos recursos naturais e possibilitam a participação mais efetiva da comunidade no processo desenvolvimento, a partir do momento em que questões subjetivas passam a nortear o trabalho de planejamento e de gestão ambientais, juntamente com as questões objetivas, normalmente empregadas.

Com base nesses pressupostos, esta pesquisa visa estudar a percepção e a conduta dos produtores rurais de Palmas (TO) em relação ao meio ambiente e aos recursos naturais em suas propriedades. Ressalta-se que é no meio rural que a relação homem-ambiente se dá de modo mais direto, justificando a necessidade do estudo perceptivo com esses grupos rurais. Acredita-se que o conhecimento da percepção, da valoração e da conduta desses sujeitos poderá contribuir para a conservação do meio ambiente e dos recursos naturais nessas porções do espaço geográfico.

Para tanto, foi feita uma abordagem com base na percepção ambiental, desenvolvida no campo da Geografia, cujos pressupostos filosóficos foram buscados inicialmente na Fenomenologia, embora posteriormente tenham sido incorporadas outras referências. A operacionalização da pesquisa obedeceu às recomendações de Whyte (1977) para os trabalhos de campo em percepção ambiental, com base no triângulo metodológico formado pela conjunção de três tipos distintos de abordagens: perguntando, ouvindo e observando. A adoção desse referencial possibilitou a compreensão de importantes aspectos subjetivos da relação entre o homem e o ambiente no contexto da zona rural do município de Palmas (TO). Este artigo, por sua vez, oferece um panorama com os principais resultados dessa pesquisa.

\section{ABORDAGEM PERCEPTIVA DO MEIO AMBIENTE}

As abordagens com base na percepção ambiental foram desenvolvidas no âmbito da Geografia e seus pressupostos filosóficos estiveram inicialmente vinculados à Fenomenologia, corrente filosófica iniciada por Edmund Husserl no princípio do século XX. Sob essa influência inicial, a percepção ambiental absorveu posteriormente outras referências, sobretudo advindas da Psicologia. Todavia, independente de sua fundamentação teórico-metodológica, o foco da percepção ambiental está no estudo da relação entre os seres humanos e o ambiente, sob o ponto de vista da subjetividade. Logo, as experiências de lugares, espaços e paisagens constituem as bases fenomenológicas da realidade geográfica, "na medida em que são diretamente experienciados como atributos do mundo-vivido" (RELPH, 1979, p. 18).

Então, a geografia, assim como outras ciências, em oposição ao padrão racional/irracional e à normalização das ciências empíricas, procurou no aporte fenomenológico a influência para inaugurar uma corrente denominada Geografia Humanística (ou Geografia da Percepção), entre os anos 1960 e 1970. Por sua vez, a Geografia Humanística buscou valorizar o estudo das percepções, das 
atitudes e dos valores dos seres humanos para com o ambiente e o espaço geográfico (AMORIM FILHO, 1987).

Portanto, para fins deste estudo, a percepção é compreendida segundo uma orientação fenomenológica, como vivência e como experiência transcendental, conforme preconizado por Husserl (BELLO, 2004). Entretanto, não é apenas a vivência da percepção o que interessa, mas todo o conjunto de outras vivências relacionadas ao meio ambiente. Nesses termos, não há como abordar somente a percepção, mas também a lembrança, a imaginação, o julgamento, dentre outras vivências, considerando suas diferentes intencionalidades.

De acordo Amorim Filho (1987), o principal pressuposto dos estudos de percepção ambiental reside no fato dos indivíduos adotarem comportamentos principalmente com base nas imagens subjetivas que têm do mundo, do que puramente no seu conhecimento objetivo. Isso justifica o suporte filosófico da fenomenologia aos estudos de cunho perceptivo.

$\mathrm{Na}$ tentativa de compreender as diferentes visões e relações subjetivas entre o ser humano e o meio ambiente, Tuan (1980) empregou os conceitos de percepção, atitude e valor e afirmou que a autocompreensão é fundamental na busca por soluções para os problemas ambientais. A percepção "é tanto a resposta dos sentidos aos estímulos externos, como atividade proposital, no qual certos fenômenos são claramente registrados, enquanto outros retrocedem para a sombra ou são bloqueados" (TUAN, 1980, p. 4). Já a atitude, é considerada primeiramente uma postura cultural, uma posição que se toma frente ao mundo, a partir de uma sucessão de experiências (percepções) que depende de uma atividade valorativa atribuída (TUAN, 1980).

Dessa forma, os conceitos de percepção, atitude e valor se aproximam da compreensão fenomenológica, principalmente quando relacionados aos conceitos de hilética e de noética (BELLO, 2004). Na percepção, propriamente dita, destaca-se o aspecto hilético, ligado à psique, porque se trata de uma vivência ligada ao instinto, à emoção e à reação por ela suscitada. Nesse sentido, relaciona-se com o contato primeiro com os objetos (ou com o mundo). Já quanto à atitude e ao valor, prevalece o aspecto noético, porque essas categorias estão ligadas a uma tomada de decisão consciente, portanto ao plano espiritual (razão, intelecto, vontade, consciência), conforme preconizado por Husserl (BELLO, 2004). Ou seja, nessas duas categorias, há uma valoração e um pensamento envolvidos, uma racionalização a partir de um impulso inicial.

Além disso, pode-se dizer também que a percepção ambiental se relaciona com a Fenomenologia por meio do próprio método fenomenológico, baseado na redução às idéias dos fenômenos (pela supressão do seu aspecto concreto e evidência do seu sentido atribuído) e na redução ao sujeito (pelo estudo das vivências dos sujeitos). Essas são características que, apesar de freqüentemente obscurecidas nos estudos de percepção ambiental, demonstram o seu vínculo seminal com a abordagem fenomenológica.

Ao incorporar essas influências, a percepção ambiental ganhou corpo na Geografia em função da crescente discussão em torno da compreensão das questões ambientais, em especial da compreensão das conexões entre percepção, comportamento e meio ambiente (AMORIM FILHO, 1987). Sendo assim, os primeiros trabalhos de percepção ambiental surgem como uma alternativa para valorizar o objetivo central da ciência geográfica, ou seja, a relação entre o homem e o ambiente, porém tomada pelo viés fenomenológico.

Como experiência primeira, a percepção influencia outros tipos de vivências de ordem concreta, o que justifica o seu estudo no campo ambiental, pois ela conduz o sujeito a adotar determinadas atitudes e valores em relação ao meio ambiente. Por conseguinte, os julgamentos, as expectativas, as ações e as condutas do homem em relação ao seu ambiente estão relacionados às experiências e vivências locais dos sujeitos, o que não pode ser explicado somente à luz do método científico tradicional.

Daí, o estudo da percepção ambiental ser de fundamental importância para que possamos compreender melhor a inter-relação entre sociedade e natureza, bem como os espaços e as paisagens construídos a partir dessa relação, objeto de estudo da Geografia. Tal relação engloba desde o 
aproveitamento dos recursos até a forma de convivência com os riscos, desde as ações de respeito para com o meio ambiente até as ações de degradação. Desse modo, a solução para os problemas ambientais, vistos como problemas humanos, depende da compreensão da subjetividade (percepções, valores e atitudes) dos sujeitos envolvidos.

\section{CARACTERIZAÇÃO DA ÁREA DE ESTUDO}

O Município de Palmas está localizado na parte central do Estado do Tocantins, região Norte do Brasil, entre as serras do Lajeado e do Carmo e a margem direita do Rio Tocantins (hoje Lago da UHE Luis Eduardo Magalhães, mais conhecida como UHE do Lajeado) e de acordo com Milagres (2009), entre as coordenadas $9^{\circ} 55^{\prime} \mathrm{S} / 10^{\circ} 30^{\prime} \mathrm{S}$ e $47^{\circ} 45^{\prime} \mathrm{W} / 48^{\circ} 30^{\prime} \mathrm{W}$ (Figura 1).

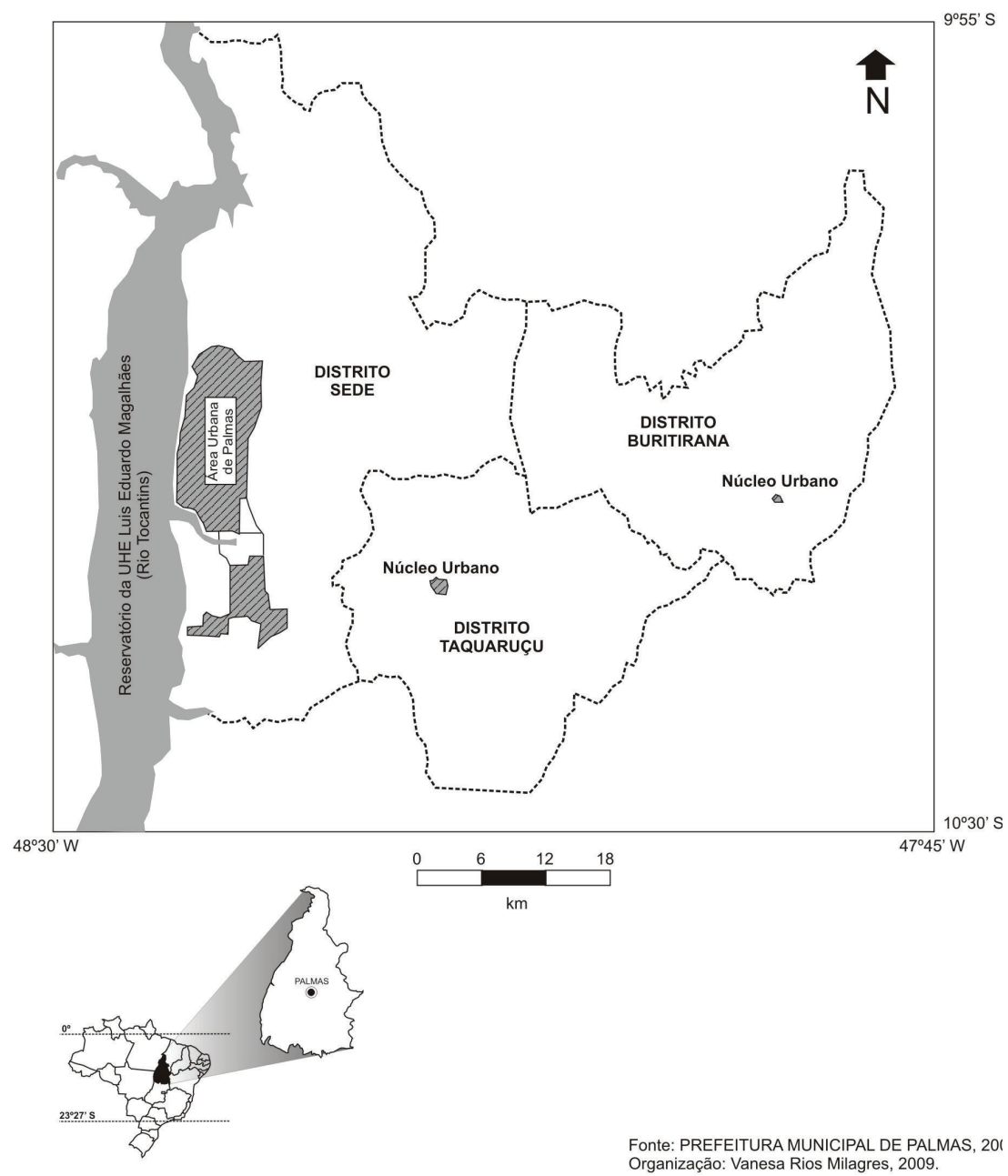

Figura 1 - Mapa de Localização do Município de Palmas (TO) e sua divisão em distritos. Fonte: Milagres (2009).

Conforme dados da Secretaria de Planejamento do Estado do Tocantins - SEPLAN (TOCANTINS, 2010), Palmas possui uma área correspondente a $2.219 \mathrm{~km}^{2}$ de extensão territorial e, conforme Instituto Brasileiro de Geografia e Estatística (IBGE), uma população de 228.297 habitantes no ano de 2010. Territorialmente, o município é constituído pelo Distrito-sede e pelos distritos de Taquaruçu e de Buritirana, conforme a Prefeitura Municipal de Palmas (2002). Em termos hidrográficos, o município está situado nas bacias do Rio das Balsas e do Rio Tocantins, as quais abrangem 11 microbacias. De acordo os dados da Base Cartográfica Digital Contínua do Estado do Tocantins (GEOTOCANTINS), disponíveis no Instituto Natureza do Tocantins (NATURATINS), a tipologia 
vegetal de Palmas é constituída de Cerrado Sentido Restrito, Formações Ciliares e de Galeria e Formações Campestres.

A Lei Complementar Municipal no 58/2002, que institui o Macrozoneamento Territorial do Município de Palmas e a Lei Complementar Municipal no 155/2007, que institui o Plano Diretor do Município de Palmas, estabelecem os tipos de uso e ocupação do solo com a delimitação de três áreas: área urbana, área de preservação e área rural.

A área rural de Palmas, cenário desta pesquisa, é definida no Plano Diretor do Município de Palmas como toda área inserida nos limites do município, que esteja localizada fora do perímetro urbano, das áreas urbanas isoladas e das áreas de urbanização específicas e de interesse turístico (PREFEITURA MUNICIPAL DE PALMAS, 2007). É basicamente ocupada por pequenos agricultores (chacareiros) com práticas de agricultura e pecuária de subsistência e para abastecimento da demanda local (feiras, supermercados etc.) com os excedentes. Segundo a Secretaria Municipal da Agricultura e Desenvolvimento Rural (SEAGRI) de Palmas, a maior parte das propriedades rurais do município são chácaras de pequeno porte que desenvolvem a agricultura familiar (milho, feijão, mandioca, hortaliças e fruticultura) e, também em pequena escala, atividades de avicultura, bovinocultura, apicultura, caprinocultura e suinocultura.

Dentre os principais problemas ambientais identificados na zona rural de Palmas (TO), destacam-se os desmatamentos e as queimadas para o desenvolvimento de práticas agropastoris. Os desmatamentos, em geral, são realizados a corte raso, ou seja, remoção total da cobertura vegetal (auxiliados de tratores com lâminas), o que impede a rebrota da flora, bem como de forma manual com motosserras e outras ferramentas. Observa-se que quando os desmates são realizados para fins de pecuária, preservam-se algumas espécies vegetais (árvores de maior porte) para servir de refúgio (sombra) ao gado, ao passo que quando se destina à agricultura, principalmente intensiva, a cobertura vegetal é toda suprimida. Já a maioria das queimadas é realizada para reformar pastagens nativas ou artificiais degradadas.

Por tudo mencionado, o trabalho aqui proposto se presta a estudar a relação do proprietário rural com o ambiente e os recursos naturais de sua propriedade no intuito de contribuir para a compreensão do próprio meio rural e dos seus habitantes. A pesquisa tem sua importância reforçada por investigar a relação que essa população mantém com o ambiente, dentro da propriedade rural uma vez que esse grupo de sujeitos pode representar não somente o Município de Palmas, mas inúmeros habitantes de outras partes do Brasil. Portanto, como são muitas as pequenas propriedades no Brasil, a conservação do ambiente depende diretamente do que acontece em tais espaços, tanto do ponto de vista da percepção quanto da conduta dos indivíduos pesquisados. Esse tipo de investigação poderá ainda contribuir para a definição de estratégias de planejamento e de gestão ambientais voltadas para a zona rural do município e para a sua população, mais especificamente. Portanto, acredita-se que o conhecimento da percepção, da valoração e da conduta dos proprietários rurais, como proposto neste estudo, pode contribuir para a preservação do meio ambiente nessas porções do espaço geográfico.

\section{METODOLOGIA}

Este estudo propõe uma abordagem com base na percepção ambiental, cujo foco está no estudo da relação entre os seres humanos e o ambiente, sob o ponto de vista da subjetividade. A operacionalização da pesquisa obedeceu às recomendações de Whyte (1977) para os trabalhos de campo em percepção ambiental, na qual as técnicas de pesquisa baseiam-se em três tipos de procedimentos: perguntando, ouvindo e observando, que juntos integram um triângulo metodológico.

Logo, os instrumentos de pesquisa foram usados de forma combinada, a fim de que pudessem se complementar. Os questionários e as entrevistas atenderam às abordagens "perguntando" e "ouvindo", respectivamente, enquanto a técnica de observação indireta atendeu à abordagem "observando". Conforme Whyte (1977), as perguntas são capazes de revelar aspectos impossíveis de 
serem observados de modo sistemático, tais como crenças, expectativas, sentimentos, preferências etc. Desse modo, questionários, entrevistas e observação complementaram-se, no sentido de se obter dados mais confiáveis e que pudessem ser confrontados. Os dados de campo foram coletados entre os meses de fevereiro e julho de 2010, diretamente nas propriedades rurais dos sujeitos, por meio das técnicas de pesquisa mencionadas.

Para atender à abordagem "perguntando" foi construído um instrumento de pesquisa contendo duas partes, sendo a primeira constituída por uma ficha de caracterização dos sujeitos e a segunda por questões abertas e fechadas, as quais foram previamente testadas e ajustadas com um grupo de 5 sujeitos à parte, com as mesmas características do grupo definitivo, ou seja, proprietários rurais do Município de Palmas (TO). Nesse teste, foram observados: a linguagem empregada nos enunciados das questões, a seqüência das perguntas e sua adequação aos objetivos da pesquisa. Por sua vez, o instrumento ajustado foi submetido a um grupo definitivo de 30 sujeitos, nos três distritos que integram o Município de Palmas: 10 no Distrito-sede, 10 no de Buritirana e 10 no de Taquaruçu. A aplicação dos questionários durou em média 30 minutos cada um, a partir do momento de abordagem do sujeito em sua propriedade rural, sendo selecionadas posteriormente algumas questões para análise do presente artigo.

A "abordagem ouvindo" foi contemplada com as entrevistas, as quais serviram para aprofundamento de algumas questões elencadas no questionário, tais como: histórico do proprietário e da propriedade; tipo de uso da propriedade e seu significado para o proprietário; impactos ambientais na propriedade e as atitudes decorrentes (de correção, mitigação); impactos ambientais nas propriedades vizinhas; uso das APP's e manutenção da reserva legal em épocas anteriores (antes da legislação e da fiscalização, mesmo em outras propriedades e/ou regiões); aprendizado com os antepassados sobre o manejo dos recursos naturais no meio rural; interesse na produção comercial ou não; e interesse por outras atividades na propriedade (mineração, turismo etc.). Essas entrevistas foram realizadas com um grupo de 6 sujeitos (dentre os 30 que responderam ao questionário), divididos entre as três categorias de proprietários rurais identificados durante a investigação: chacareiros que vivem da agricultura de subsistência e comercial de pequeno porte; fazendeiros que praticam agropecuária comercial; e chacareiros que utilizam seus imóveis para lazer e turismo. A escolha de tais sujeitos se deu por meio da análise dos questionários e do contato realizado durante sua aplicação, quando foram identificados aqueles sujeitos que melhor representassem suas categorias, que demonstrassem possuir informações mais ricas sob o ponto de vista de suas vivências e que estivessem dispostos a colaborar com a pesquisa, dispondo de tempo para a realização de uma abordagem mais aprofundada.

Para atender à "abordagem observando" foi utilizada a observação indireta com o objetivo de se verificar as formas de utilização dos recursos naturais pelo produtor. Para tanto, foi aplicada a técnica da observação indireta, através da presença do pesquisador nas 30 propriedades visitadas. No âmbito da percepção ambiental, conforme Whyte (1977), esta técnica utiliza como indicadores de comportamento os efeitos produzidos pela ação humana no ambiente, que no caso deste trabalho compreendem: indícios de queimadas e de desmatamentos, utilização de áreas de preservação permanente, feições erosivas, presença de lixo, dentre outros. Por outro lado, foi possível também a identificação de suas iniciativas no campo da gestão ambiental no espaço da propriedade como, por exemplo, a preservação da reserva legal e das APP's, o controle de erosão, o manejo da água, dentre outras.

Adicionalmente, a análise de documentos (fornecidos pelos órgãos competentes) permitiu reforçar ou corrigir alguns pontos da pesquisa e caracterizar o cenário da investigação. Entre esses documentos, podem-se listar: dados e informações, mapas, cartas-imagens e legislação referente ao tema estudado. Dentre os órgãos públicos visitados, destacam-se: Instituto Natureza do Tocantins (NATURATINS), Instituto de Terras do Estado do Tocantins (ITERTINS), Instituto de Desenvolvimento Rural do Tocantins (RURALTINS - Escritório Local e Sede de Palmas), Instituto Nacional 
de Colonização e Reforma Agrária (INCRA), Instituto Brasileiro do Meio Ambiente e dos Recursos Naturais Renováveis (IBAMA), Agência de Defesa Agropecuária do Tocantins (ADAPEC), Secretaria de Planejamento do Estado do Tocantins (SEPLAN), Secretaria Municipal de Agricultura e Desenvolvimento Rural de Palmas (SEAGRI), Secretaria de Desenvolvimento Urbano, Meio Ambiente e Habitação de Palmas (SEDUMAH) e Prefeitura Municipal de Palmas.

\section{RESULTADOS E DISCUSSÃO}

\section{Caracterização dos sujeitos}

O grupo que participou da pesquisa inicialmente foi formado por um total de 30 sujeitos, sendo 28 homens e 02 mulheres, todos residentes no Município de Palmas (TO). Com relação à idade desses indivíduos, observou-se uma grande amplitude entre o sujeito mais jovem (com 17 anos) e o sujeito mais idoso (com 83 anos), sendo que a média do grupo permaneceu em torno dos 50 anos. Isso demonstra que se trata de sujeitos experientes e com acúmulo de vivências em função da média de idade, os quais são de naturalidade de vários estados da federação, além de um estrangeiro, natural dos Estados Unidos da América (EUA).

Entre os pesquisados se verificou a existência de 3 grupos de sujeitos, os quais podem-se listar: o primeiro grupo foi constituído por 16 proprietários rurais que são na realidade pequenos chacareiros que vivem da agropecuária de subsistência, mas que desenvolvem também uma agropecuária comercial de pequeno porte e vendem os produtos ou excedentes (hortaliças, galinhas, mandioca, etc.) para as feiras e supermercados locais. Esse grupo possui um modo de produção ainda de certa forma artesanal e predomina em todo município de Palmas; o segundo grupo foi formado 9 proprietários rurais que praticam agropecuária em grande escala comercial, principalmente bovinocultura de corte e cultivo de soja, todos no Distrito de Buritirana, os quais usam tecnologias para melhoramento da produção, como inseminação artificial, correção de solos com calcário, sementes selecionadas e adaptadas ao cerrado; e, por último, o terceiro grupo formado por 5 sujeitos do Distrito de Taquaruçu, cujos imóveis são destinados às atividades de lazer e turismo, tanto para própria família e amigos (em três imóveis), como para exploração comercial (em dois imóveis).

De modo geral, a pesquisa revelou o perfil dos proprietários rurais do Município de Palmas (TO), os quais são, em sua maior parte, constituídos de sujeitos autóctones e de sujeitos oriundos de Estados vizinhos. Possuem pouco tempo de moradia local, em função do pouco tempo de criação do Estado do Tocantins (22 anos). Todavia, tais sujeitos apresentam experiências prévias no meio rural e têm baixa escolaridade. Sendo assim, entende-se que esse grupo de sujeitos pode representar não somente o Município de Palmas, mas inúmeros habitantes de outras partes do Brasil rural.

\section{PERCEPÇÃO AMBIENTAL E CONDUTA DOS PROPRIETÁRIOS RURAIS DE PALMAS (TO)}

Quanto à percepção e à valoração dos produtores rurais em relação às características ambientais de suas propriedades:

Os resultados da primeira questão do instrumento de pesquisa, O que é meio ambiente para você?, estão contidos na Tabela 1. Os dados demonstram que a maior parte dos sujeitos possui uma concepção estritamente ecológica do meio ambiente, na qual se ressaltam a natureza e seus elementos como o ecossistema, a vegetação (plantas e matas), os animais, a água (córregos e rios), a terra e o ar. Contudo, observa-se que entre tais sujeitos que compartilham da mencionada concepção do meio ambiente, existem dois subgrupos. O primeiro, composto por 12 sujeitos, com uma percepção puramente ecológica e acrescida por questões de conservação e preservação da natureza. Já o segundo grupo, formado por 9 indivíduos com essa mesma percepção, porém com um viés utilitário dos componentes ambientais. 
MIRANDA, N. M.; SOUZA, L. B.

Tabela 1 - "O que é meio ambiente para você?"

\begin{tabular}{l|c}
\multicolumn{1}{c|}{ TIPO DE CONCEPÇÃo } & № DE RESPOSTAS \\
\hline $\begin{array}{l}\text { Concepção estritamente ecológica + conservação e preservação da natu- } \\
\text { reza }\end{array}$ & 12 \\
\hline Concepção estritamente ecológica + caráter utilitário da natureza & 09 \\
\hline Concepção holística & 03 \\
\hline Não sabem & 06 \\
\hline TOTAL & 30 \\
\hline
\end{tabular}

Por outro lado, um grupo de 3 sujeitos apresentou uma concepção mais abrangente do meio ambiente (holística), ainda que os mesmos não se incluíssem no referido meio. Esse fato provavelmente se explica pela própria concepção do mundo, a qual é eivada de dualismos como entre o homem e a natureza, o céu e o inferno, a vida e a morte, o que Tuan (1980) chama de oposição binária, comum a vários tipos de civilizações, mas especialmente presente na cultura ocidental. Apesar disso, tais sujeitos se colocam numa posição de centralidade em relação ao meio ambiente e a seus componentes percebidos. Nesse sentido, o ambiente é concebido como algo que cerca o ser humano por todos os lados e que está por toda parte, embora não o inclua necessariamente, já que o "eu" é o ponto de referência para o qual convergem os fenômenos percebidos, devido à intencionalidade.

Outro grupo formado por 6 sujeitos afirmou não saber responder a indagação. Isso provavelmente se explica pelo fato da baixa escolaridade dos proprietários e pelo termo "meio ambiente" ter sido empregado com mais evidência a partir da segunda metade do século XX, em função da problemática ambiental em torno da exploração e conservação dos recursos naturais. Todavia, a aparente dificuldade por um esforço conceitual não invalida ou nega uma "visão de mundo" e uma larga experiência perceptiva com o ambiente por parte dessas pessoas. Pode indicar, inclusive, que a relação com o ambiente seja mais experiencial do que conceitual.

Percebe-se então, de imediato, que a questão supramencionada evidencia um esforço conceitual por parte do sujeito, portanto transpõe o caráter puramente perceptivo, embora não o exclua como base real, empírica, a partir da qual são confrontadas as idéias e informações recebidas de outros sujeitos, tanto pela formação quanto pela herança cultural. Por isso, uma simples definição do que seja o meio ambiente pode trazer consigo uma enorme carga de idéias e de percepções prévias recebidas, vivenciadas e construídas pelo sujeito.

Os resultados da questão, Como você classifica sua propriedade rural em termos ambientais? Justifique, mostram que 17 sujeitos consideram suas propriedades preservadas, 9 sujeitos as consideram muito preservadas e 4 sujeitos consideram-nas pouco preservadas. Os dois primeiros grupos justificaram suas respostas de maneira semelhante, os quais apontaram que evitam o desmatamento (13 sujeitos), preservam as reservas legais e as áreas de proteção permanente (7 sujeitos), utilizam apenas as áreas já abertas e/ou antropizadas (3 sujeitos), preservam a água e não poluem os córregos (2 sujeitos), evitam as queimadas (2 sujeitos), recuperam as áreas degradadas e fazem plantio de árvores (2 sujeitos), conservam a natureza "que Deus deixou" (2 sujeitos) e adotam práticas de contenção de erosão e assoreamento (1 sujeito).

Entretanto, a percepção de um dos sujeitos contrasta com os demais sujeitos que têm uma tendência de conservação e preservação da natureza e seus recursos ambientais. O referido sujeito, em entrevista, afirmou que sua propriedade é muito preservada porque o Naturatins (órgão ambiental estadual) não permite desmatar além do estabelecido por lei. Sendo assim, demonstra que as práticas de conservação podem ser adotadas exclusivamente ou prioritariamente por força de lei, e não necessariamente pela consciência do proprietário sobre a importância dessas práticas.

Por outro lado, um grupo de 4 sujeitos considera suas propriedades pouco preservadas e atribuiu suas respostas ao fato das mesmas já estarem desflorestadas. Segundo os sujeitos, os mencionados 
desmatamentos foram realizados por antigos proprietários e eles somente reformam as áreas para cultivar as lavouras temporárias e as pastagens. De certa maneira, a transferência da responsabilidade para outras pessoas é uma forma de isenção de culpa pelos referidos problemas ambientais, o que não exime os proprietários de buscar soluções para minimizar os mesmos.

Nota-se que a maioria dos sujeitos percebe uma grande quantidade de atributos e indicadores de qualidade ambiental na propriedade rural, mostrando de certa forma a inter-relação entre os componentes físicos e bióticos. Contudo, os mesmos normalmente não evocam componentes legais e institucionais, considerando que a percepção da qualidade ambiental também passa por critérios técnicos, à luz da norma e da fiscalização ambientais. É importante salientar que tais critérios, em alguns casos, tornam-se os principais parâmetros de referência para a qualidade ambiental, juntamente com a experiência perceptiva e julgamento do sujeito, com base em seus próprios critérios (que são subjetivos).

Nos apontamentos da terceira questão, Quais os recursos naturais mais importantes/significativos em sua propriedade?, houve uma valoração maior da água e da vegetação por parte da maioria dos sujeitos (Tabela 2). Esses dois elementos têm significado importante para os sujeitos, uma vez que são sinônimos de valorização das propriedades rurais, em termos econômicos. Tal valorização ocorre porque a água e a vegetação estão relacionadas às condições de sobrevivência no meio rural, isto é, as áreas que possuem esses elementos são propícias para o desenvolvimento das principais atividades: agricultura e a pecuária de pequeno porte, assim como o turismo e as atividades de recreação vinculadas à água.

Tabela 2 - "Quais os recursos naturais mais importantes/significativos em sua propriedade?"

\begin{tabular}{l|c}
\multicolumn{1}{c|}{ TIPO DE RESPOSTAS } & № DE RESPOSTAS \\
\hline Água & 23 \\
\hline Vegetação (matas) & 09 \\
\hline Córregos e nascentes & 04 \\
\hline Gado & 04 \\
\hline Terra (solo) & 03 \\
\hline Serra & 02 \\
\hline Mata ciliar & 02 \\
\hline Animais & 01 \\
\hline Pasto & 01 \\
\hline \multicolumn{1}{c}{ TOTAL } & 49 \\
\hline
\end{tabular}

Portanto, pode-se ter uma conduta ligada à conservação desses elementos, a partir dessa valoração, sobretudo quando dependem diretamente dos recursos naturais. Porém, esse tipo de conduta, apesar de estar de acordo com os pressupostos ecológicos e sociais de conservação, pode mascarar a percepção e a valoração dos recursos apenas como elementos indispensáveis ao propósito econômico de uma atividade produtiva voltada para o mercado.

Outro elemento importante para manutenção dos referidos recursos ambientais é o solo, o qual obteve poucas indicações. Entretanto, ressalta-se que uma conduta irresponsável com o solo, produzirá efeitos diretos sobre a água, por meio da erosão e do assoreamento dos cursos d'água. Embora o solo seja essencial para a manutenção de outros recursos, os sujeitos não o exaltaram como um recurso ambiental dos mais significativos, no âmbito das propriedades rurais. Esse fato ocorre provavelmente em função da baixa fertilidade das terras por causa de sua acidez, o que demanda cuidados especiais como a correção com calcário.

Quanto à questão Existe algum tipo de problema ambiental na sua propriedade?, verificou-se que um grupo de 25 sujeitos não percebe e outro grupo formado por 5 sujeitos percebe algum tipo problema em tais áreas. Esse último grupo destacou a falta de conservação dos córregos, inclusive 
o desmatamento das áreas de proteção permanente, as queimadas e a erosão como os maiores problemas ambientais existentes. A referida erosão (voçorocamento) ocorre em função da prática de garimpos de exploração de ouro que existiu no município num passado recente.

Por ocasião das observações de campo, a questão dos problemas ambientais foi verificada nas propriedades rurais, o que permitiu algumas constatações importantes. Dentre elas, ressalta-se que a maioria dos proprietários rurais não percebe os impactos ambientais existentes em suas propriedades ou não reagem negativamente frente a esses impactos, considerando-os problemas, tais como os desmatamentos e as queimadas. Na realidade, os desmatamentos e as queimadas irregulares, ou seja, sem autorização do órgão ambiental, correspondem aos principais problemas ambientais da zona rural de Palmas uma vez não obedecem a medidas de controle ou mitigação, exceto aquelas advindas da experiência dos sujeitos.

Apesar dos impactos existirem de modo objetivo, segundo critérios técnicos e legais, os mesmos não são percebidos como algo negativo e sério, motivo de preocupação e de uma conduta corretiva por parte de muitos sujeitos. Isso mostra como a intencionalidade, que condiciona e limita a percepção, pode assumir diferentes formas, conduzindo a diferentes interpretações dos objetos. No mesmo sentido, as experiências prévias e os valores cultivados por esses sujeitos poderão conduzir a uma percepção cujo aspecto hilético não esteja baseado em reações negativas suscitadas pelas propriedades sensíveis dos objetos, que nesse caso são os impactos ambientais no meio rural. Nesse caso, a percepção habituada e os valores principalmente voltados aos componentes econômicos levam a uma reação indiferente ao ambiente impactado, que por sua vez pode não ser uma prioridade para o sujeito.

Observa-se que os impactos ambientais gerados pelo fogo são os mais comuns na zona rural de Palmas em função de serem, em muitas propriedades, as principais alternativas de preparo do solo para cultivo de lavouras e reforma de pastagens. As áreas impactadas ou degradadas, em geral, são fiscalizadas pelo órgão ambiental do Estado quando são motivadas por denúncias, as quais são muitas vezes dos próprios vizinhos ou confrontantes. Observou-se ainda que em tais áreas, principalmente nas APP's, as iniciativas de correção dos danos ambientais são incipientes e partem dos próprios sujeitos, limitando-se ao plantio de espécies vegetais sem projetos específicos de recuperação de áreas degradadas, submetidos ao órgãos ambientais.

Os resultados da questão "Selecione as fotografias nas quais você identifica algum tipo de problema com o meio ambiente; descreva o tipo de problema identificado em cada uma das fotografias selecionadas", estão contidos no Quadro 1. Nessa questão, os 30 sujeitos que participaram da pesquisa deveriam identificar os impactos ambientais em todas as fotografias apresentadas, o que não aconteceu. Os impactos foram identificados dentro de uma variação entre 14 e 25 sujeitos, dependendo da fotografia. Isso mostra que, apesar da imagem retratar claramente um impacto ambiental, alguns indivíduos sequer conseguem perceber a essência daquela imagem. Dentre os problemas identificados, destacam-se os desmatamentos, as queimadas, a erosão e o lixo.

Em outros casos, os indivíduos até poderão perceber o impacto, mas poderão não ter reações desejáveis frente ao problema, como comentado em questão anterior. Então, caso o impacto não seja percebido ou caso não se tenha reação frente a ele, não haverá ação corretiva por parte do sujeito. Logo, o aspecto noético refletirá o aspecto hilético, ou seja, uma percepção indiferente e uma reação instintiva indiferente levarão a uma valoração indiferente e a uma conduta indiferente frente ao problema. A forma dada a uma reação indiferente é uma conduta indiferente. 
Quadro 1 - "Selecione as fotografias nas quais você identifica algum tipo de problema com o meio ambiente; descreva o tipo de problema identificado em cada uma das fotografias selecionadas".

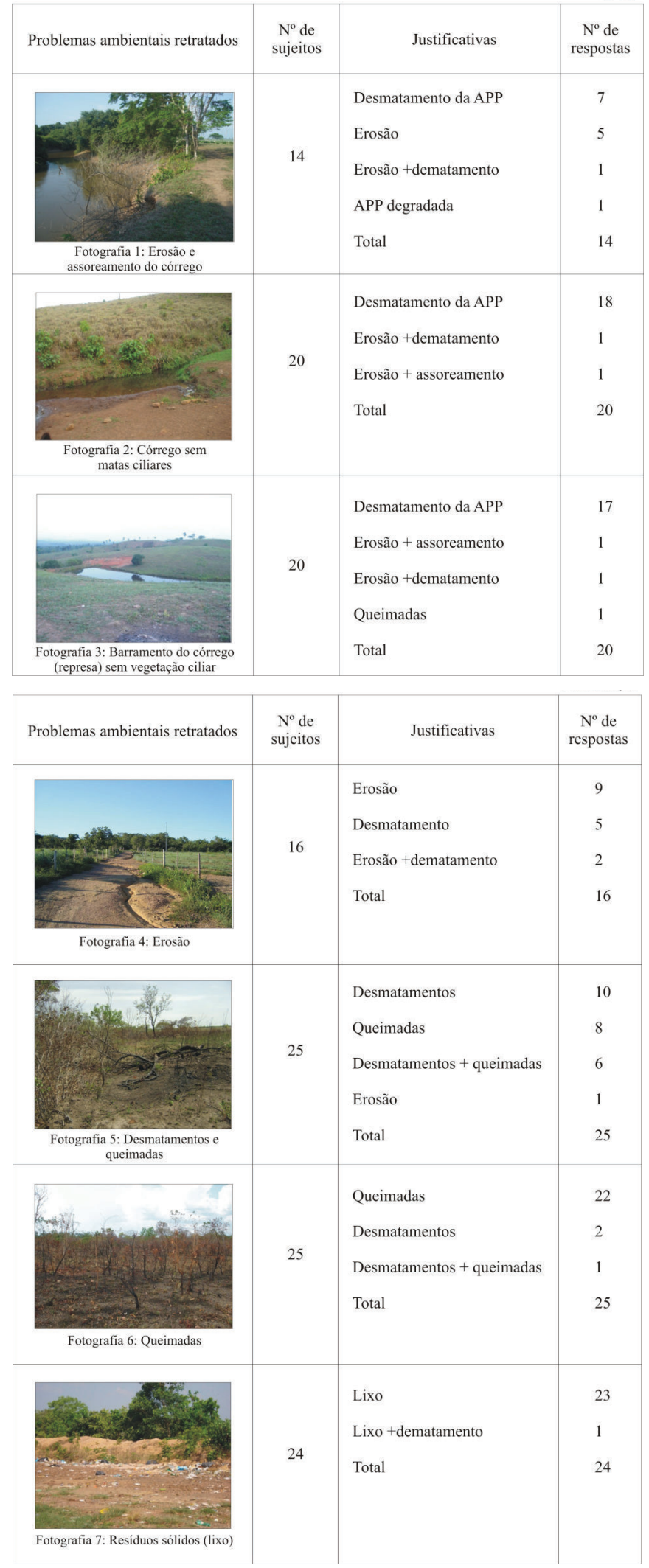


Quanto à conduta dos produtores rurais em relação às formas de utilização dos recursos naturais em suas propriedades, identificando suas iniciativas no campo da gestão ambiental:

No quarto questionamento, você tem algum tipo de cuidado para preservar a natureza em sua propriedade? Se sim, qual?, todos os sujeitos responderam positivamente a indagação. Os proprietários rurais apresentaram justificativas diversificadas, tais como: evitar desmatamentos (17), evitar queimadas (13), não jogar lixo em local inadequado e disposição correta do mesmo (5), preservar a reserva legal e/ou APP (3), não utilizar agrotóxicos (3), coibir a caça (2), evitar práticas causadoras de erosão (1), plantar árvores (1), poda, capina e tratamento do solo com calcário (1) e conservar os animais (1).

Dessa maneira, percebe-se que muitas práticas foram apontadas pelos sujeitos para preservar a natureza no espaço de suas propriedades rurais. Contudo, isso não se traduz no interior de algumas das propriedades rurais observadas, nas quais foram constatados impactos ambientais como desmatamentos, falta de conservação da APP, queimadas e disposição incorreta de lixo. Dentre estes, somente os desmatamentos figuram como uma das irregularidades ambientais mais notificadas e autuadas pelo órgão ambiental do Estado. Conforme informações do referido órgão, além dos desmatamentos, a pesca, as atividades poluidoras e o transporte de madeira ilegal são as irregularidades mais freqüentes na zona rural de Palmas.

A adoção dos tipos de abordagem "perguntando", "ouvindo" e "observando", propostos por Whyte (1977) permitiram o confronto de dados diferentes, o que revela as contradições entre algumas respostas subjetivas e os aspectos objetivos observados nas propriedades. De fato, como a sensibilidade de alguns sujeitos mostrou-se relativamente indiferente aos impactos ambientais, considerando o aspecto hilético da percepção, era esperado que o aspecto noético também refletisse essa característica, embora o discurso procurasse mostrar algo diferente.

Na Tabela 3 estão contidos os resultados da indagação O que é possível fazer para cuidar do meio ambiente na zona rural de Palmas? Quem seria responsável por isso? A maioria dos proprietários sugeriu ações imediatas e diretas nas propriedades rurais, tais como: evitar desmatamentos e queimadas (19), preservar as APP's e recuperar áreas degradadas (5), não jogar lixo em local impróprio (3), fiscalização (2), não poluir os rios e conservar a água (3), utilizar áreas já abertas (1) e coibir a caça e a pesca (1), ao passo que 7 ações sugeridas foram direcionadas especificamente para os sujeitos, como subsidiar os proprietários para preservar (4) e orientar para preservar (3). Os sujeitos afirmaram que tais ações, de modo geral, são de responsabilidades de todos os envolvidos com a gestão do meio ambiente na zona rural de Palmas, ou seja, dos próprios proprietários, governo, estado, prefeitura e órgãos ambientais. Isso mostra que os proprietários, apesar de assumirem parte da responsabilidade, aguardam por apoio técnico, legal e financeiro dos entes públicos envolvidos com ações no meio rural. Isso também denota que, caso estejam sozinhos, dificilmente esses proprietários conduzirão o processo de cuidado ambiental de um modo satisfatório, o que ressalta o papel dos órgãos públicos e das políticas públicas nesse setor.

Nota-se que o discurso empregado em tais respostas muitas vezes não condiz com tipos de uso observados nas propriedades rurais, conforme mencionado anteriormente. São, em muitos casos, respostas vagas e que não implicam em sugestões efetivas para a conservação ambiental. Observa-se ainda que tal questão também não está presente em termos práticos nas temáticas prioritárias do poder público por meio principalmente dos órgãos ambientais.

Quanto à questão $\mathrm{O}$ que você faz com o lixo produzido no imóvel?, constatou-se que a maioria dos proprietários (17 sujeitos) dão destinação final aos resíduos sólidos no próprio imóvel, por meio das práticas de queima (16 sujeitos) e enterramento (1 sujeito) dos mesmos. Por outro lado, um grupo de 11 sujeitos afirmou que o destino final do lixo é fora das propriedades rurais, sendo que em oito destes imóveis existe coleta pela Prefeitura de Palmas e, em cinco, os próprios levam os resíduos para o Aterro Sanitário de Palmas. Este último fato ocorre em função da proximidade das propriedades em relação ao referido aterro. Ressalta-se ainda que 4 sujeitos afirmaram que utilizam o lixo orgânico em seus imóveis, como adubo. 
Tabela 3 - “O que é possível fazer para cuidar do meio ambiente na zona rural de Palmas? Quem seria responsável por isso?"

\begin{tabular}{|c|c|c|}
\hline AÇÕES SUGERIDAS PELOS SUJEITOS & $\begin{array}{c}\text { ATOR (ES) RESPONSÁVEL (EIS) } \\
\text { PELA AÇÃO }\end{array}$ & № DE RESPOSTAS \\
\hline Evitar desmatamentos e queimadas & Proprietários, Estado, Ibama & 19 \\
\hline Preservar APP's e recuperar áreas degradadas & Proprietários, Prefeitura, Estado & 05 \\
\hline Subsidiar os proprietários para preservar & Prefeitura, Estado, Governo & 04 \\
\hline Não jogar lixo em local impróprio & Proprietários & 03 \\
\hline Orientação para preservar & Naturatins, Ibama, proprietários & 03 \\
\hline Não poluir os rios/conservar a água & Estado, proprietários & 03 \\
\hline Fiscalização & Ibama, Prefeitura, Naturatins & 02 \\
\hline Utilizar áreas já abertas & Proprietários & 01 \\
\hline Coibir caça e pesca & Proprietários & 01 \\
\hline TOTAL & & 41 \\
\hline
\end{tabular}

Cabe ressaltar que, na percepção da maioria dos sujeitos, a queima do lixo produzido é a solução imediata encontrada para o problema dos resíduos sólidos. Embora tal prática não seja tecnicamente correta, na idéia dos proprietários o fato do lixo "desaparecer" com a queima pode parecer a solução ideal para o problema (que também “desaparece"), sobretudo porque os prejuízos causados na atmosfera não produzem efeitos diretos, imediatos e facilmente perceptíveis às pessoas. A percepção do lixo como problema conduz a uma solução rápida, fácil e de baixo custo, que é a queima dos resíduos. O uso do fogo, por sua vez, revela o seu poder de "transformação" e de "limpeza", freqüentemente atribuídos pela percepção das pessoas, sobretudo no meio rural e, mais particularmente, na área abrangida pelo Cerrado brasileiro, onde o fogo é largamente empregado para o manejo de pastos e de áreas agrícolas.

Ressalta-se ainda que o lixo produzido no meio rural é, em parte, muito semelhante ao lixo urbano, em função do consumo dos mesmos produtos. Isso, provavelmente vem contribuindo para o aumento da quantidade de lixo produzido no meio rural, se comparado a épocas anteriores, inclusive com os resíduos tóxicos provenientes de defensivos e insumos agrícolas como os fertilizantes e os praguicidas.

Com relação ao questionamento sobre as áreas mais férteis das propriedades e suas formas de utilização, os resultados podem ser observados na Tabela 4. Destacam-se dois grupos de sujeitos: 12 proprietários consideram as áreas que margeiam os córregos como as mais férteis da propriedade e as utilizam para atividades agropecuárias e de preservação, e 11 proprietários consideram férteis todas as áreas de suas propriedades, utilizando-as para atividades agropastoris. Nota-se que as respostas desse primeiro grupo revelam uma questão contraditória da parte mais fértil ser também a parte de uso proibido, ou seja, as APP's, as quais são tanto utilizadas como preservadas. Mais uma vez, a percepção ocorre de acordo com uma intencionalidade diferente daquela esperada pela abordagem técnica e jurídica. Intencionam-se as margens dos cursos d'água não como áreas de preservação (dotadas de biodiversidade e de função limitadora da erosão e do assoreamento), mas como áreas férteis, capazes de sustentar culturas agrícolas e de gerar retorno produtivo ao proprietário da terra.

Os resultados da questão, Você utiliza técnicas de desmatamentos e queimadas nas atividades de preparo do solo?, apontam que 26 proprietários não utilizam essas técnicas por se tratar de atividades agressivas e danosas ao meio ambiente. Dentre estes últimos, 1 sujeito ressaltou ainda que utiliza apenas as áreas antropizadas não havendo necessidade de novos desmatamentos ou queimadas. Outro grupo formado por 4 sujeitos afirmou que utilizam as referidas práticas, apresentando as seguintes justificativas: para limpar a terra e aproveitar os resíduos da queimada como adubo (2), renovar o pasto (1), desmatar para plantar soja (1). Desse total, 3 sujeitos afirmaram que não têm licença e 1 que tem licença do órgão ambiental do Estado para as realização dos desmatamentos e queimadas. 
Assim como salientado anteriormente, as queimadas são utilizadas culturalmente como forma de manejo do solo, em todo o Cerrado brasileiro, sobretudo para pastagens nativas que requerem esse tipo de técnica. Portanto, controlar essa prática também não é tarefa simples, por ser arraigada e fazer parte das práticas culturais dos proprietários rurais, além de ser uma técnica barata e rápida. Nesse caso, o fogo está relacionado com "limpeza" da área, enquanto o "mato" está ligado à "sujeira".

Por outro lado, a formação de pasto com espécies exóticas, como a braquiária, pode representar um impacto mais significativo sobre o ambiente natural, uma vez que a biodiversidade é afetada com a competição entre as espécies exóticas e nativas. Além disso, as pastagens artificiais também provocam danos e até mesmo destroem algumas espécies faunísticas locais.

Tabela 4 - "Quais são as áreas mais férteis de sua propriedade? De que modo você utiliza essas áreas?"

\begin{tabular}{l|l|c}
\hline \multicolumn{1}{c|}{ ÁREAS FÉRTEIS DO IMÓVEL } & \multicolumn{1}{|c}{ FORMA DE UTILIZAÇÃO } & № DE RESPOSTAS \\
\hline Áreas margeando os córregos & Atividades agropastoris e preservação & 12 \\
\hline Toda a propriedade & Atividades agropastoris & 11 \\
\hline As áreas de matas & Preservação & 01 \\
\hline As áreas planas & Atividades agropastoris & 01 \\
\hline A chapada no alto do morro & Não respondeu & 01 \\
\hline As áreas de encostas dos morros & Preservação & 01 \\
\hline As áreas próximas à sede do imóvel & Atividades agropastoris & 01 \\
\hline Não é fértil & & 01 \\
\hline Não soube responder & & 01 \\
\hline TOTAL & & 30 \\
\hline
\end{tabular}

Embora muitos proprietários informem que não usam o fogo, foram detectados restos de queimadas durante os trabalhos de campo mencionados anteriormente. Contudo, foram detectadas queimadas, desmatamentos, disposição incorreta de lixo, dentre outros, em muitas áreas da zona rural de Palmas, especialmente nas margens das rodovias, o que denota uma valoração e uma conduta pouco comprometidas com a qualidade ambiental. Essa característica se torna ainda patente no caso dos espaços de uso comum, como as rodovias e as estradas rurais, já que em muitas vezes o bem coletivo não é percebido e tratado do mesmo modo que o bem particular. Ressalta-se que no ano de 2010 o fogo atingiu grande parte da zona rural de Palmas, em função da estiagem prolongada e das queimadas irregulares e descontroladas praticadas pelos proprietários rurais. A queima realizada na estação seca possibilita a rebrota do capim durante o período chuvoso vindouro.

\section{CONSIDERAÇÕES FINAIS}

O estudo sobre a percepção ambiental dos proprietários rurais de Palmas (TO) em relação ao ambiente e aos recursos naturais de sua propriedade procurou se basear no caráter de redução aos sujeitos e às suas idéias. A maioria dos sujeitos possui uma concepção estritamente ecológica e utilitária do meio ambiente, na qual se ressaltam a natureza e seus elementos como o ecossistema, a vegetação, os animais, a água, a terra e o ar. Até certo ponto, demonstram preocupação com a questão da preservação da natureza, pelo menos em seus discursos. Contudo, parte dos sujeitos não soube responder à indagação referente ao conceito de meio ambiente, possivelmente em função da baixa escolaridade e da sua relação com o ambiente ser mais experiencial do que conceitual.

Os proprietários classificam seus imóveis, em termos ambientais, como preservados e como muito preservados, devido à percepção de uma grande quantidade de atributos e indicadores subjetivos de qualidade ambiental na propriedade rural e também por afirmarem não provocar danos ambientais ou práticas danosas ao ambiente, como o desmatamento e as queimadas. Entretanto, a atribuição da qualidade ambiental se faz com base na experiência perceptiva e no conseqüente 
julgamento dos sujeitos, uma vez que não foram evocados componentes legais e institucionais, por meio de indicadores objetivos ou quantitativos.

Quanto à existência de problemas ambientais nas propriedades, verifica-se que a maioria dos sujeitos não percebe os impactos existentes ou não reagem de modo esperado frente a esses impactos, considerando os problemas como desmatamentos e queimadas irregulares, observados durante o trabalho de campo. Por isso, os proprietários têm uma reação indiferente, tendo em vista que a percepção e os valores estão voltados prioritariamente aos componentes econômicos do ambiente. Assim, os aspectos noéticos refletem os aspectos hiléticos, isto é, a não percepção ou a reação indiferente frente ao problema ambiental não levam a uma ação ou a uma conduta corretiva em relação ao mesmo.

Quando indagados sobre suas ações, os sujeitos responderam que têm vários cuidados para preservar a natureza. Porém, foram observados impactos ambientais nas propriedades rurais observadas, tais como: desmatamento, falta de conservação da APP, queimadas, disposição incorreta de lixo, dentre outros. Dentre as ações sugeridas para cuidar do meio ambiente, destacam-se as ações imediatas e diretas nas propriedades rurais, tais como: evitar desmatamentos e queimadas e preservar as APP's. Tais ações, segundo os sujeitos, são de responsabilidades dos próprios proprietários e do poder público. Demonstram, com isso, que esperam por auxílio estatal para a solução dos problemas ambientais.

A maior parte do lixo produzido tem sua destinação final nos próprios imóveis por meio da queima do mesmo, o que não é a solução tecnicamente correta para o problema, porque contamina a atmosfera e pode aumentar os riscos de incêndios florestais. A prática de queimada também está associada à limpeza das áreas para manejo de pastos e áreas agrícolas e é uma prática culturalmente arraigada.

A maioria dos sujeitos considera as áreas que margeiam os córregos (APP's) como as mais férteis dos imóveis e as utilizam tanto para atividades agropecuárias quanto para preservação, ou seja, nesse caso a percepção ocorre de acordo com uma intencionalidade (de conservação ou de exploração). O caráter utilitário do ambiente de uso proibido segundo as normas ambientais, que é o caso das APP's, é atribuído por se tratar de uma área com maior fertilidade do solo e boa disponibilidade hídrica. Em alguns casos, o valor produtivo se sobrepõe ao valor ecológico dessas áreas.

Em termos gerais, o estudo da percepção ambiental dos proprietários rurais demonstrou nuances importantes da relação entre o homem e a natureza na Zona Rural do Município de Palmas (TO). Esse aspecto reforça a importância de investigações nesse campo, sobretudo se for considerado que os sujeitos pesquisados podem representar vários habitantes de outros espaços rurais do Brasil. Portanto, esse tipo de análise demonstrou, além do seu componente geográfico e interdisciplinar, o potencial pragmático da investigação, uma vez que fornece subsídios para a elaboração de propostas nos campos da preservação e da educação ambiental, voltados aos proprietários rurais.

\section{REFERÊNCIA BIBLIOGRÁFICA}

AMORIM FILHO, O. B. O contexto teórico do desenvolvimento dos estudos humanísticos e perceptivos na Geografia. In: AMORIM FILHO, O. B.; CARTER, H.; KOHLSDORF, M. E. Percepção ambiental: contexto teórico e aplicações ao tema urbano. Belo Horizonte: Departamento de Geografia; Instituto de Geociências; Universidade Federal de Minas Gerais, 1987. (Publicação Especial, n.5).

BELLO, A. A. Fenomenologia e ciências humanas. Bauru: EDUSC, 2004.

INSTITUTO BRASILEIRO DE GEOGRAFIA E ESTATÍSTICA. Cidadesat. Disponível em: < http://www. ibge.gov.br/cidadesat/topwindow.htm?1>. Acesso em: 18 mar. 2011.

MILAGRES, V. R. Paisagem e efeitos do turismo: uma abordagem perceptiva com os moradores do Distrito de Taquaruçu, Palmas (TO). 2009. 155 f. Dissertação (Mestrado em Ciências do Ambiente), Universidade Federal do Tocantins, Palmas, 2009. 
PREFEITURA MUNICIPAL DE PALMAS. Instituto de Planejamento Urbano de Palmas. Caderno de Revisão do Plano Diretor de Palmas: Plano Diretor de Ordenamento Territorial. Palmas, TO, 2002.

PREFEITURA MUNICIPAL DE PALMAS. Lei Complementar n. ${ }^{0}$ 058. Palmas, TO. 16 set. 2002. Disponível em: $<$ http://www.palmas.to.gov.br>. Acesso em: 25 ago. 2006.

PREFEITURA MUNICIPAL DE PALMAS. Lei Complementar n. ${ }^{\circ}$ 155. Palmas, TO. 28 dez. 2007. Disponível em: <http://www.palmas.to.gov.br>. Acesso em: 04 mai. 2010.

RELPH, E. C. As bases fenomenológicas da Geografia. Revista de Geografia. Rio Claro, SP, v. 4, n. 7, p. 1-25, abr. 1979.

RIBEIRO, A. M. Ecologizar: pensando o ambiente humano. Belo Horizonte: Rona, 2000.

TOCANTINS (Estado). Secretaria de Planejamento do Estado do Tocantins. Atlas do Tocantins 2008. Diponível em: <http://www.seplan.to.gov.br/seplan/br/download/20080929093220-atlas_do_tocantins_2008_portugues.pdf >. Acesso em: 04 mai. 2010.

TUAN, Y. Topofilia: um estudo da percepção, atitudes e valores do meio ambiente. São Paulo, SP: Difel, 1980. WHYTE, A. V. T. Guidelines for fields studies in environmental perception. Paris: UNESCO, 1977.

Trabalho enviado em outubro de 2011

Trabalho aceito em novembro de 2011 